\title{
KFBD
}

Karadeniz Fen Bilimleri Dergisi

The Black Sea Journal of Sciences

ISSN (Online): 2564-7377

Araștırma Makalesi / Research Article

\section{Epoksiisoindol Türevi bir Bileşiğin Moleküler Modelleme Çalışmaları}

\author{
Ersin TEMEL ${ }^{1 *}$, Can ALAŞALVAR ${ }^{1}$ \\ ${ }^{1}$ Giresun Üniversitesi, Teknik Bilimler Meslek Yüksekokulu, Elektrik ve Enerji Bölümü, Giresun, Türkiye
}

Geliş Tarihi: 02.12.2018

"Sorumlu Yazar: ersin.temel@giresun.edu.tr

Kabul Tarihi: 18.12 .2018

\section{$\ddot{\mathbf{O z}}$}

Bu çalışmada epoksiisoindol türevi olan 2-metil-3a,4,7,7a-tetrahidro-1H-4,7-epoksiisoindol-1,3(2H)-dion bileşiği kuramsal olarak incelenmiştir. Literatürde söz konusu bileşiğin endo ve ekso izomerleri mevcuttur. Bu izomerler başlangıç noktası alınarak moleküller optimize edildi. Optimize yapılar kullanılarak moleküllerin HOMO-LUMO orbitalleri ve elektrostatik potansiyel yüzeyleri (EPS) çizdirildi. İlave olarak moleküllerin paketlenme davranışlarını anlamak için Hirshfeld yüzeyleri ve parmak izi diyagramları çizdirildi. Hesaplamalarda DFT B3LYP/6-311 baz seti kullanildı.

Anahtar Kelimeler: Epoksiisoindol, Yoğunluk Fonksiyoneli Teorisi, Hirshfeld Yüzeyi.

\section{Molecular Modellig Studies of an Epoxyisoindole Derivative Compound}

\begin{abstract}
In this study, 2-methyl-3a, 4,7,7a-tetrahydro-1H-4,7-epoxyisoindole-1,3 (2H) -dione compound, which is an epoxyisoindole derivative, has been studied theoretically. In the literature, the endo and exo isomers of the compound are present. These isomers were taken as starting geometry to optimize the molecules. HOMO-LUMO orbitals and electrostatic potential surfaces (EPS) of molecules were drawn by using optimized structures. Additionally, Hirshfeld surfaces and fingerprint diagrams were drawn to understand the packaging behavior of the molecules. DFT B3LYP/ 6311 base set was used in the calculations.
\end{abstract}

Keywords: Epoxyisoindole, Density Functional Theory, Hirshfeld Surface. 


\section{Giriş}

Norkantiridin, geleneksel Çin tıbbında çok farklı türde kanser türlerini özellikle karaciğer karsinomunu tedavi etmek için kullanılan kantaridinin demetile edilmiş türevidir (Chen et al., 2009; Li et al., 2014; Liu et al., 2017). Norkantaridin önemli bir anti kanser aktiviteye sahip olduğu gibi aynı zamanda kemik iliğini uyararak lökosit sayısını artırır ve diğer ajanların neden olduğu lökopeni üzerinde antagonistik etkiye sahiptir (Gurven and Hill, 2010; Yang et al., 2011). Klinik olarak norkantiridin esas olarak serin / treonin protein fosfataz 1 ve 2A'nın (PP1 ve PP2A) bir inhibitörü olarak etki eder ve oral veya intravenöz yolla uygulanabilir (Tarleton et al., 2012; Kadioglu et al., 2014). Ancak tüm avantajlarına rağmen norkantiridinin klinik uygulamaları çeşitli nedenlerden dolayı sinırlıdır (Zeng and Sun, 2009; Zhao et al., 2015). Norkantiridinin çeşitli türevleri yan etkileri azaltmak ve terapötik etkiyi artırmak için araştırılmıştır. Araştırmacılar protein fosfataz enzimine ve daha az toksisite profillerine karşı yüksek aktiviteye sahip yeni ve daha güçlü türevler üzerine çalışmaya devam etmektedir (Cheng et al., 2016). Son elli yıl boyunca norkantiridin-platin kompleks içeren binlerce analog ve türev sentezlendi. Bu analoglar her türlü anti tümör aktivitesini göstermiştir ve her birinin kendine özgü aktivitesi vardır. Azotla modifiye edilen kantiridin/norkantiridin türevleri anti kanser ajanı olarak potansiyel olarak kullanışlıdır.

Bildiğimiz gibi, köprüdeki ve anhidrit döngüsündeki heteroatomların türü çok önemlidir, ancak çift bağın varlığı aktivitede çok az etkiye sahiptir. Bu çalışmada norkantiridinin yapısal olarak benzeri olan norkantirimid türevi olan 2-methyl-3a,4,7,7a-tetrahydro-1H-4,7-epoxyisoindole1,3(2H)-dione molekülü kuramsal olarak incelenmiştir.

\section{Materyal ve Metot}

Çalışmaya konu olan molekülün kristal yapısı Goh ve arkadaşları tarafından 2008 tarihinde sunulmuştur (Yit, Pool and White, 2008). Bu çalışmaya göre molekülün endo ve ekzo olmak üzere iki izomeri vardır. Bu izomerlere ait kristalografik bilgi dosyaları (cif) Cambridge Kristalografik Data Merkezinden (CCDC) elde edilmiştir (CCDC numaraları: 666549, 666551). Hesaplamalar için başlangıç noktası olarak cif dosyalarından elde edilen geometriler kullanılmıştır. Moleküllere ait kuramsal hesaplamalarda, molekülün gaz fazındaki kararlı yapısı, enerjisi ve birçok moleküler özelliklerinin belirlenmesi amaçlandı. Kuantum mekaniksel hesaplamalarda, Gaussian 09W (Frisch, M. J.; Trucks, G.W.; Schlegel, H. B.; Scuseria, G. E.; Robb, M. A.; Cheeseman, J. R.; Scalmani, G.; Barone, V.;Mennucci, B.; Petersson, G. A.; Nakatsuji, H.; Caricato, M.; Li, X.; Hratchian, H. P.; Izmaylov, A. F.; Bloino, J.; Zheng, G.; Sonnenber, 2009) yazılımı içinde bulunan Yoğunluk Fonksiyoneli Kuramı (YFK) yöntemiyle geometri optimizasyonu yapıldı. Optimize edilecek 
molekül GaussView 05 programı kullanılarak görselleştirildi (Dennington, Keith and Milliam, 2009). YFK hesaplamaları 6-311 baz seti yardımıyla gerçekleştirildi ve bu hesaplamalarda, yerel olmayan Lee-Yang-Parr (LYP) korelasyon fonksiyoneliyle (Lee, Yang and Parr, 1988) sistemin etkileşimsiz temsiline ait HF kesin çözümlerinden elde edilen ve geleneksel yerel spin yoğunluk değiş-tokuş enerji fonksiyonelini harmanlayan Becke'nin üç parametreli melez değiş-tokuş korelasyon fonksiyoneli (B3LYP) (Becke, 1992) kullanıldı. Optimizasyon süresince Berny optimizasyon algoritması kullanıldı. Hesaplamalara YFK yöntemiyle konformasyonel analiz yapılarak devam edildi ve elektrostatik potansiyel yüzeyleri çizdirildi. Molekülün HOMO-LUMO orbitalleri çizdirildi ve enerji değerleri hesaplandı. Sonuçları görselleştirmek ve yorumlamak için GaussView 05 yazılımı kullanıldı (Dennington, Keith and Milliam, 2009). Moleküller arası etkileşimleri incelemek için CrystalExplorer yazılımı yardımıyla Hirshfeld yüzeyleri ve parmak izi histogramları çizdirildi (Wolff et al., 2012).

\section{Bulgular ve Tartışma}

\subsection{2-methyl-3a,4,7,7a-tetrahydro-1H-4,7-epoxyisoindole-1,3(2H)-dione molekülünün} optimize yapısı

Literatür çalışmalarında molekülün iki adet izomerinin olduğu görülmektedir(Yit, Pool and White, 2008). Endo ve ekso izomerlere ait X-1şını kırınımı metodu sonucunda elde edilmiş moleküler yapılar Şekil 1'de görülmektedir. Moleküle ait bazı geometrik parametreler karşılaştırmalı olarak Tablo 1'de verilmiştir. Ayrıca X-Işını verisinden elde edilen yapı ile optimize edilen yapı üst üste örtüştürülmüştür (Şekil 2). Örtüşme sonucunda ekso izomerde RMSE değeri 0.050 elde edilirken endo izomerde bu değer 0.034 olarak hesaplanmıştır. Şekil 1-2 ve Tablo 1 incelendiğinde deneysel olarak elde edilen yapı ile optimize edilen yapı arasında oldukça iyi bir uyum olduğu görülmektedir.

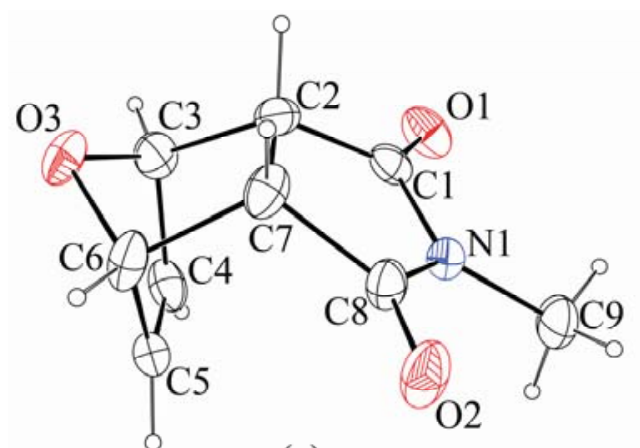

(a)

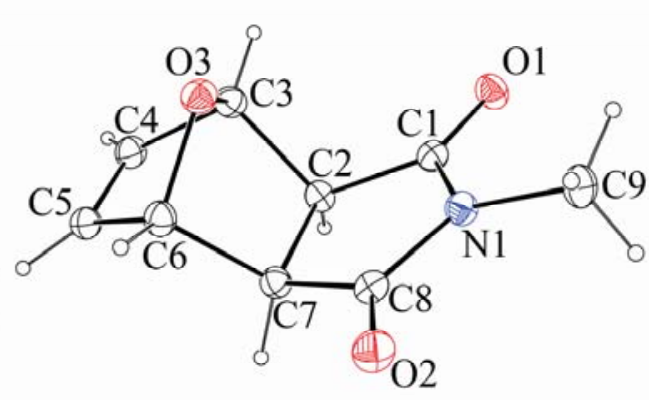

(b)

Şekil 1. Bileşiğin moleküler yapısı (a) endo izomer (b) ekso izomer 


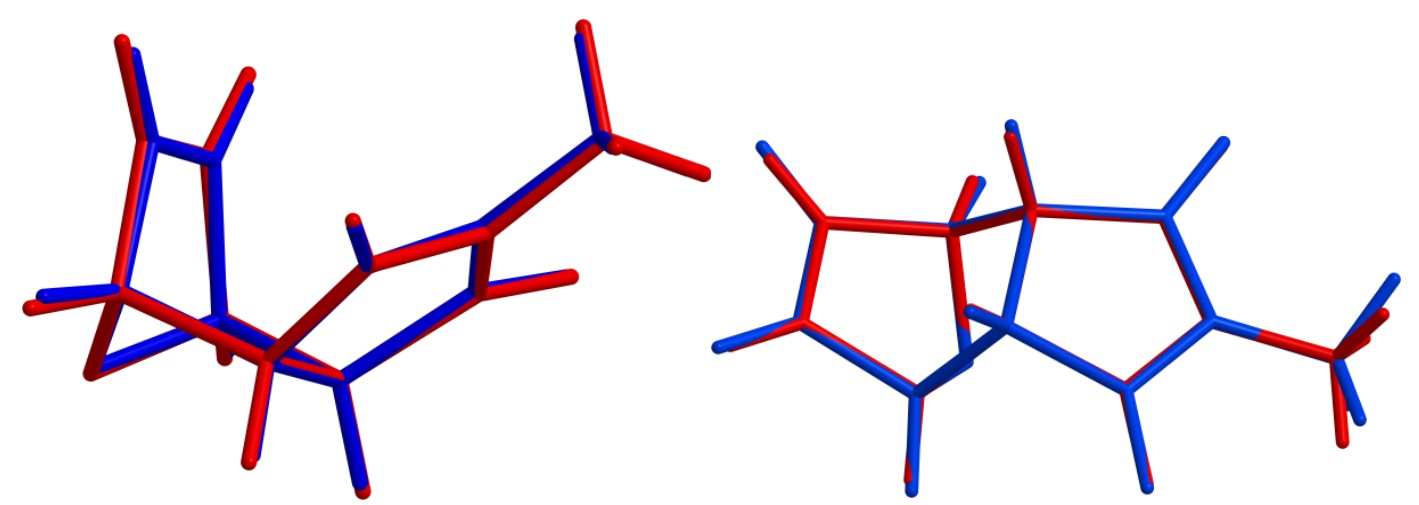

Şekil 2. Endo ve ekso izomerler için X-1şını verisinden elde edilen yapı ile optimize edilen yapının üst üste örtüştürülmesi (kırmızı, X-Işını kırınımı yöntemiyle elde edilen yapı; mavi, optimize edilen yapı)

Tablo 1. Bazı geometrik parametrelerin karşılaştırmalı tablosu.

\begin{tabular}{|c|c|c|c|c|}
\hline \multicolumn{5}{|c|}{ Bağ uzunlukları (Å) } \\
\hline & \multicolumn{2}{|c|}{ Ekso izomer } & \multicolumn{2}{|c|}{ Endo izomer } \\
\hline Băg & X-Işını & Hesaplama & X-Işıını & Hesaplama \\
\hline $\mathrm{C1}-\mathrm{C2}$ & $1.503(3)$ & 1.519 & $1.505(2)$ & 1.515 \\
\hline C1-N1 & $1.381(2)$ & 1.396 & $1.3855(19)$ & 1.4005 \\
\hline C1-O1 & $1.212(2)$ & 1.236 & $1.2100(19)$ & 1.3687 \\
\hline $\mathrm{C} 2-\mathrm{C} 3$ & $1.571(2)$ & 1.573 & $1.564(2)$ & 1.579 \\
\hline $\mathrm{C} 2-\mathrm{C} 7$ & $1.526(2)$ & 1.557 & $1.543(2)$ & 1.553 \\
\hline C3-C4 & $1.500(3)$ & 1.524 & $1.514(2)$ & 1.523 \\
\hline C3-O3 & $1.438(2)$ & 1.487 & $1.4425(19)$ & 1.4876 \\
\hline C4-C5 & $1.322(3)$ & 1.339 & $1.323(2)$ & 1.339 \\
\hline C5-C6 & $1.498(3)$ & 1.524 & $1.515(2)$ & 1.523 \\
\hline C6-O3 & $1.435(2)$ & 1.487 & $1.4430(19)$ & 1.4876 \\
\hline C6-C7 & $1.568(3)$ & 1.573 & $1.564(2)$ & 1.579 \\
\hline C7-C8 & $1.512(2)$ & 1.519 & $1.511(2)$ & 1.515 \\
\hline C8-O2 & $1.210(2)$ & 1.236 & $1.2119(19)$ & 1.2369 \\
\hline C8-N1 & $1.380(2)$ & 1.396 & $1.383(2)$ & 1.400 \\
\hline N1-C9 & $1.457(2)$ & 1.461 & $1.4550(19)$ & 1.4605 \\
\hline \multicolumn{5}{|c|}{ Bă̆ açıları $\left({ }^{\circ}\right)$} \\
\hline & \multicolumn{2}{|c|}{ Ekso izomer } & \multicolumn{2}{|c|}{ Endo izomer } \\
\hline Açı & X-Iş̧ını & Hesaplama & X-Işıını & Hesaplama \\
\hline C1-C2-C3 & $115.45(15)$ & 111.74 & $111.37(12)$ & 116.19 \\
\hline $\mathrm{C} 4-\mathrm{C} 3-\mathrm{C} 2$ & $107.63(14)$ & 107.17 & $105.81(12)$ & 108.52 \\
\hline $\mathrm{O} 3-\mathrm{C} 3-\mathrm{C} 2$ & $99.77(14)$ & 99.60 & $100.91(11)$ & 98.80 \\
\hline $\mathrm{C6}-\mathrm{O} 3-\mathrm{C} 3$ & $95.60(12)$ & 95.38 & $95.96(11)$ & 95.33 \\
\hline $\mathrm{O} 3-\mathrm{C} 3-\mathrm{C} 4$ & $102.27(15)$ & 101.45 & $102.10(12)$ & 101.39 \\
\hline $\mathrm{O} 3-\mathrm{C6}-\mathrm{C} 5$ & $102.32(14)$ & 101.45 & $101.99(12)$ & 101.39 \\
\hline C5-C6-C7 & $107.15(14)$ & 107.19 & $106.06(13)$ & 108.52 \\
\hline C8-C7-C6 & $115.47(15)$ & 111.72 & $111.10(12)$ & 116.19 \\
\hline
\end{tabular}




\subsection{2-methyl-3a,4,7,7a-tetrahydro-1H-4,7-epoxyisoindole-1,3(2H)-dione molekülünün HOMO ve LUMO analizi}

Kimyasal reaksiyonda yer alan ana orbitaller olan en yüksek işgal edilmiş orbital (HOMO) ve en düşük işgal edilmemiş orbital (LUMO) sınır orbitalleri olarak ta adlandırılır. Bu nedenle HOMO elektronlarla dolu olan en dış orbitali ifade eder ve bir elektron vericisi olarak davranırken LUMO elektronlarla dolu olmayan en iç orbital olarak düşünülebilir ve bir elekron alıcısı olarak davranır. HOMO enerjisi doğrudan iyonizasyon potansiyeli ile ilgilidir ve elektron verme yeteneğini temsil eder. LUMO enerjisi ise doğrudan elektron ilgisi ile ilgilidir ve elektron kabul etme yeteneğiyle ilişkilidir. HOMO ve LUMO arasında oluşan enerji aralığı moleküler kimyasal kararlılığa işaret eder. HOMO-LUMO arasındaki bu enerji aralığı moleküler elektriksel iletim özelliklerini belirlemek için kritik bir parametredir. Büyük bir HOMO-LUMO enerji aralığına sahip olan moleküller sert olarak adlandırılırken küçük bir HOMO-LUMO enerji aralığına sahip olan moleküller yumuşak moleküller olarak adlandırılır. HOMO ve LUMO görüntüleri Şekil 4'te görülmektedir. Endo izomerde HOMO-LUMO enerji aralığı $-6.07 \mathrm{eV}$ olarak hesaplanırken bu veri ekso izomer için $-6.12 \mathrm{eV}$ olarak hesaplanmıştır. HOMO-LUMO enerji aralığının ekso izomerde çok az büyüktür.
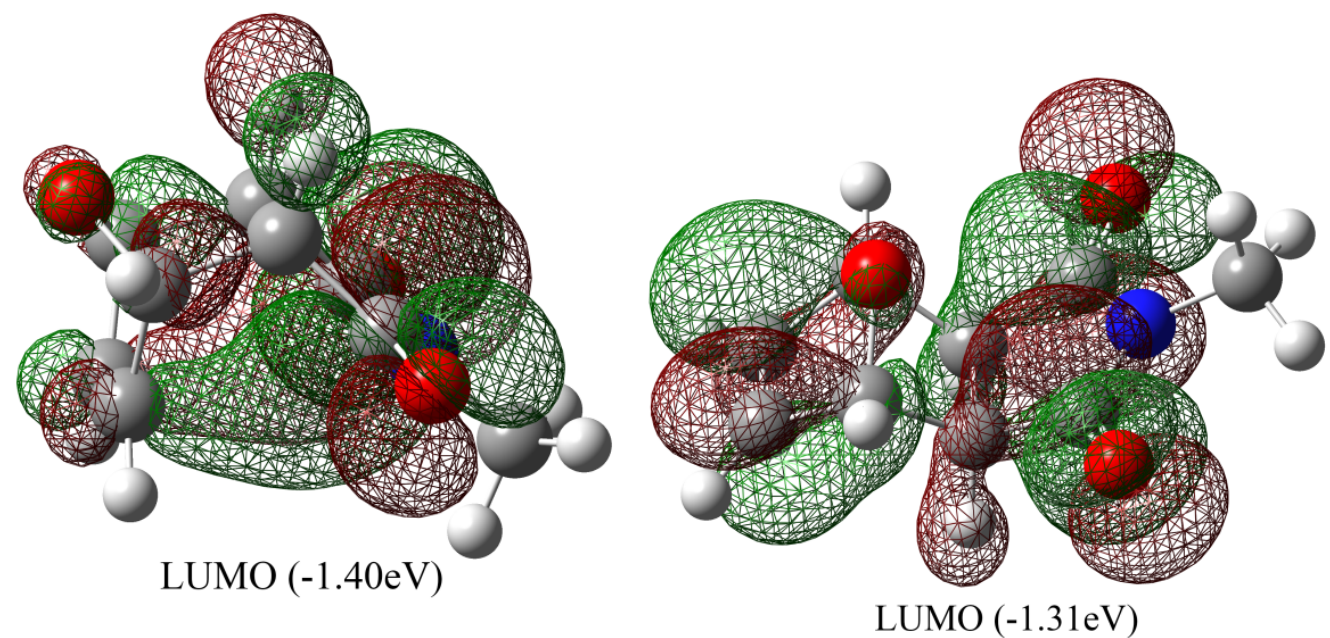

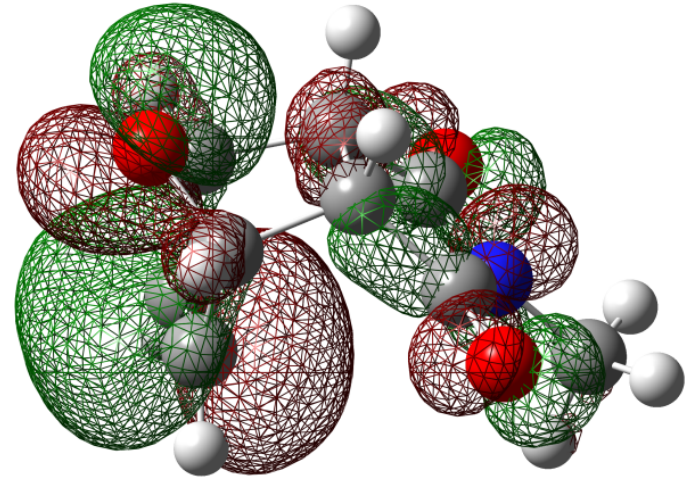

$\operatorname{HOMO}(-7.47 \mathrm{eV})$

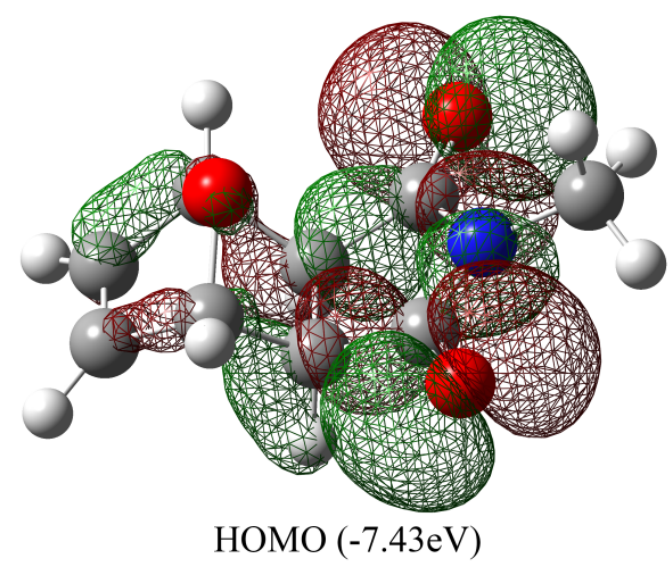

Şekil 4. Moleküllerin HOMO-LUMO çizimleri 


\subsection{2-methyl-3a,4,7,7a-tetrahydro-1H-4,7-epoxyisoindole-1,3(2H)-dione molekülünün moleküler elektrostatik potansiyeli}

Molekülde olası moleküller arası etkileşimlerin yerlerini bulmak için moleküler elektrostatik potansiyeller (MEPs) kullanılabilir. Son zamanlarda MEP'ler, elektrofilik ve nükleofilik reaksiyonlar için bağıl reaktifliğin tahmin edilmesi, moleküller arası bağlanma etkileşimlerini, moleküler istiflenme ve paketlenme ve çeşitli makroskopik özelliğin tahmini için kullanılmaktadır. MEP molekülün toplam yük dağılımı ile ilişkili olduğu için kısmi yükler, dipol momentler, moleküllerin elektronegatifliği ve kimyasal reaktivitesi gibi moleküler özellikler arasındaki korelasyonu sağlar.

$\mathrm{Bu}$ çalışmada yüzeydeki elektrostatik potansiyeller farklı renklerle temsil edilmektedir (Şekil 4). Kırmızı renk negatif elektrostatik potansiyel bölgesini temsil ederken mavi bölge pozitif elektrostatik potansiyeli temsil eder. Yeşil renkli bölgeler ise sıfır potansiyelli bölgeleri temsil eder. Potansiyelin negatif bölgeleri elektrofilik reaktiflik ile ilgiliyken pozitif olanlar nükleofilik reaktiflik ile ilgilidir. Şekil 5 incelendiğinde her iki izomerde de kırmızı bölgelerin oksijen atomlarının üzerinde yoğunlaştı̆̆ görülmektedir.

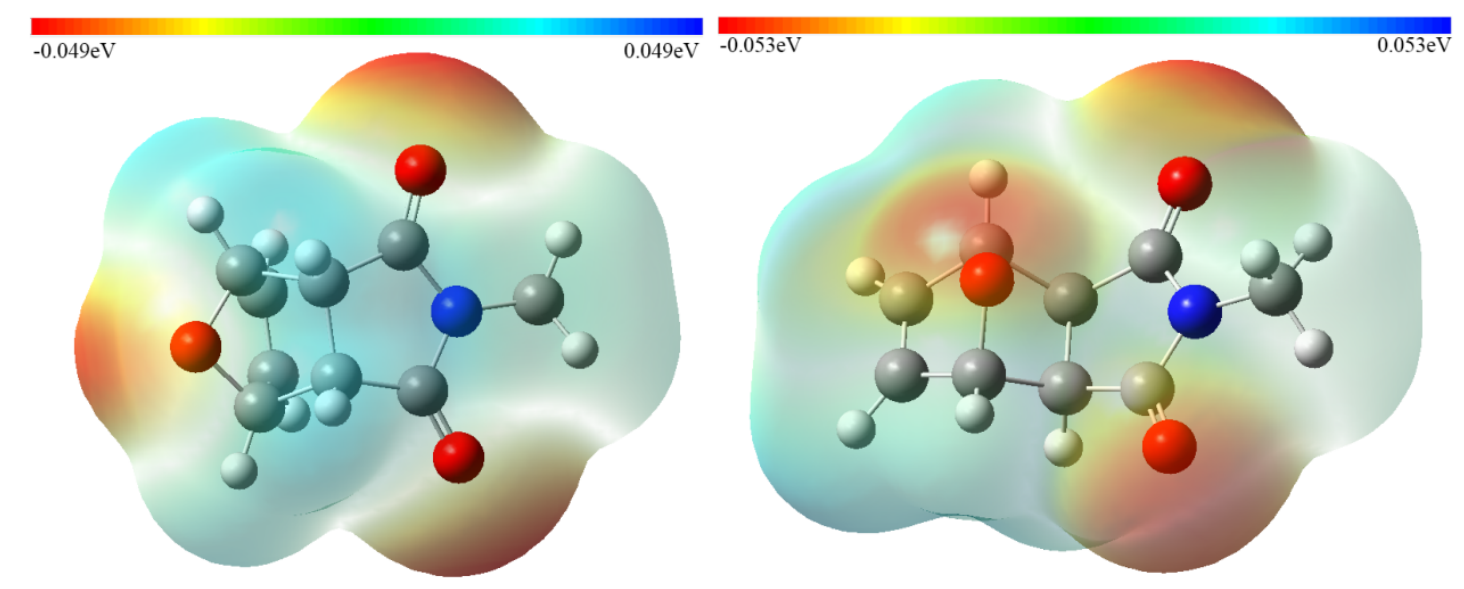

Şekil 5. Moleküllerin elektrostatik potansiyel yüzey haritaları

\subsection{2-methyl-3a,4,7,7a-tetrahydro-1H-4,7-epoxyisoindole-1,3(2H)-dione molekülünün Hirshfeld Yüzeyi}

Hirshfeld yüzey analizi bir kristalde moleküller arası etkileşimler hakkında bilgi elde etmek için oldukça yararlı bir araçtır. Hirshfeld yüzeyleri van der Waals mesafelerini görselleştirmek için ve moleküller arası etkileşim noktalarını belirlemek için kullanılır. Yüzeyler $d_{\text {norm }}$ fonksiyonuna göre haritalandırıldı. $d_{\text {norm }}$ değeri $d_{i}$, de parametreleri ve van der Waals yarıçapları ile ilişkilidir. $d_{i}$, Hirshfeld yüzeyinden yüzey içindeki en yakın atoma olan uzaklığı temsil ederken $\mathrm{d}_{\mathrm{e}}$ bu yüzeyden 
yüzeyin dışındaki en yakın atoma olan mesafeyi temsil etmektedir. Yüzey üzerinde dikkat çeken üç renk vardır (kırmızı, mavi, beyaz). Kırmızı renkli bölgeler van der Waals yarıçapı toplamından daha k1sa olan temas bölgelerini göstermektedir ve negatif $d_{\text {norm }}$ değerine sahiptir. Mavi renkli bölgelerde ise moleküller arası mesafe van der Waals yarıçapları toplamından daha uzundur. Beyaz bölgelerde moleküller arası mesafeler van der Waals yarıçapları toplamına eşittir ve dnorm sıfıra eşittir. Şekil 6 ve 7'de görüldüğü gibi kırmızı bölgeler oksijen atomlarının, epoksi halkasındaki hidrojen atomları ve metil hidrojen atomları üzerinde bulunmaktadır. Ayrıca pirol halkasının ortasında da kırmızı bir bölge bulunmaktadır. Şekilden anlaşılacağı gibi paketlenme C-H...O tipi hidrojen bağlarıyla sağlanmaktadır. 3 boyutlu Hirshfeld yüzeyi di ve de mesafeleri kullanılarak 2 boyutlu histogramlara indirgenebilir. $\mathrm{Bu}$ histogramlar parmak izi çizimleri olarak adlandırılır ve moleküller arası etkileşimlerin bağıl katkıları ve tipleri hakkında bilgi verir. Histogramlar incelendiğinde her iki izomerde de en baskın etkileşimin $\mathrm{H}-\mathrm{H}$ etkileşmelerinden geldiği görülmektedir (endo izomer için \%48.3 ve ekso izomer için \%45.7). Ardından en baskın etkileşim endo izomer için \%42.7 ve ekso izomer için \%41.8 ile O-H/H-O etkileşmelerinden kaynaklanmaktadır. Histogramlar incelendiğinde sivri piklerin olduğu bölgelerin $\mathrm{O}-\mathrm{H} / \mathrm{H}-\mathrm{O}$ yakınlaşmalarının olduğu bölgelere karşılık geldiği ve buralarda moleküller arası yakınlaşmaların en yakın olduğu bölgelere karşılık geldiği görülebilir. $\mathrm{Bu}$ da O-H tipi bağlanmaların olduğunu göstermektedir. 

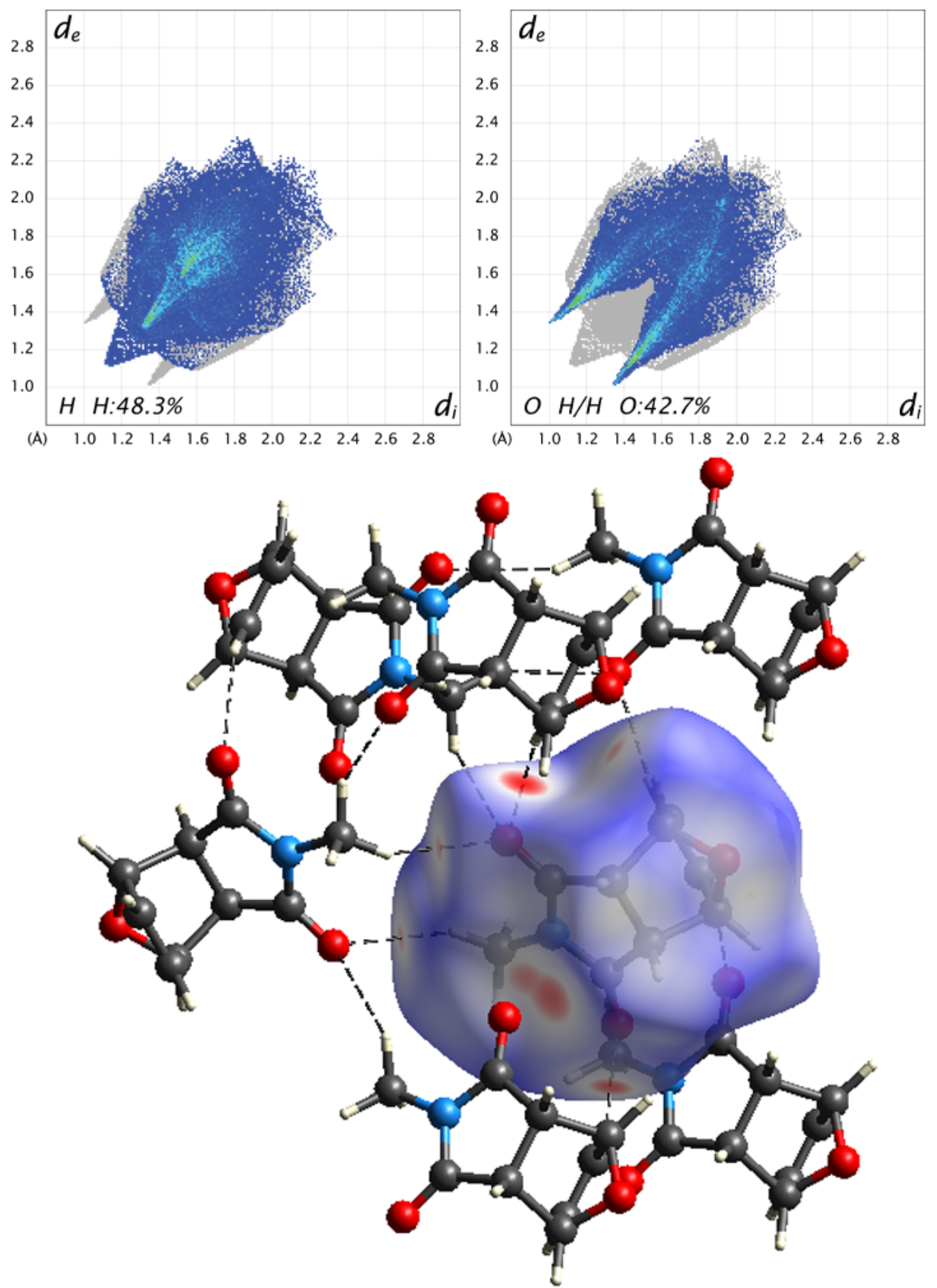

Şekil 6. Endo izomer için Hirshfeld yüzeyi ve parmak izi histogramları (en büyük katkıya sahip olan etkileşmelere ait histogramlar gösterilmektedir. 

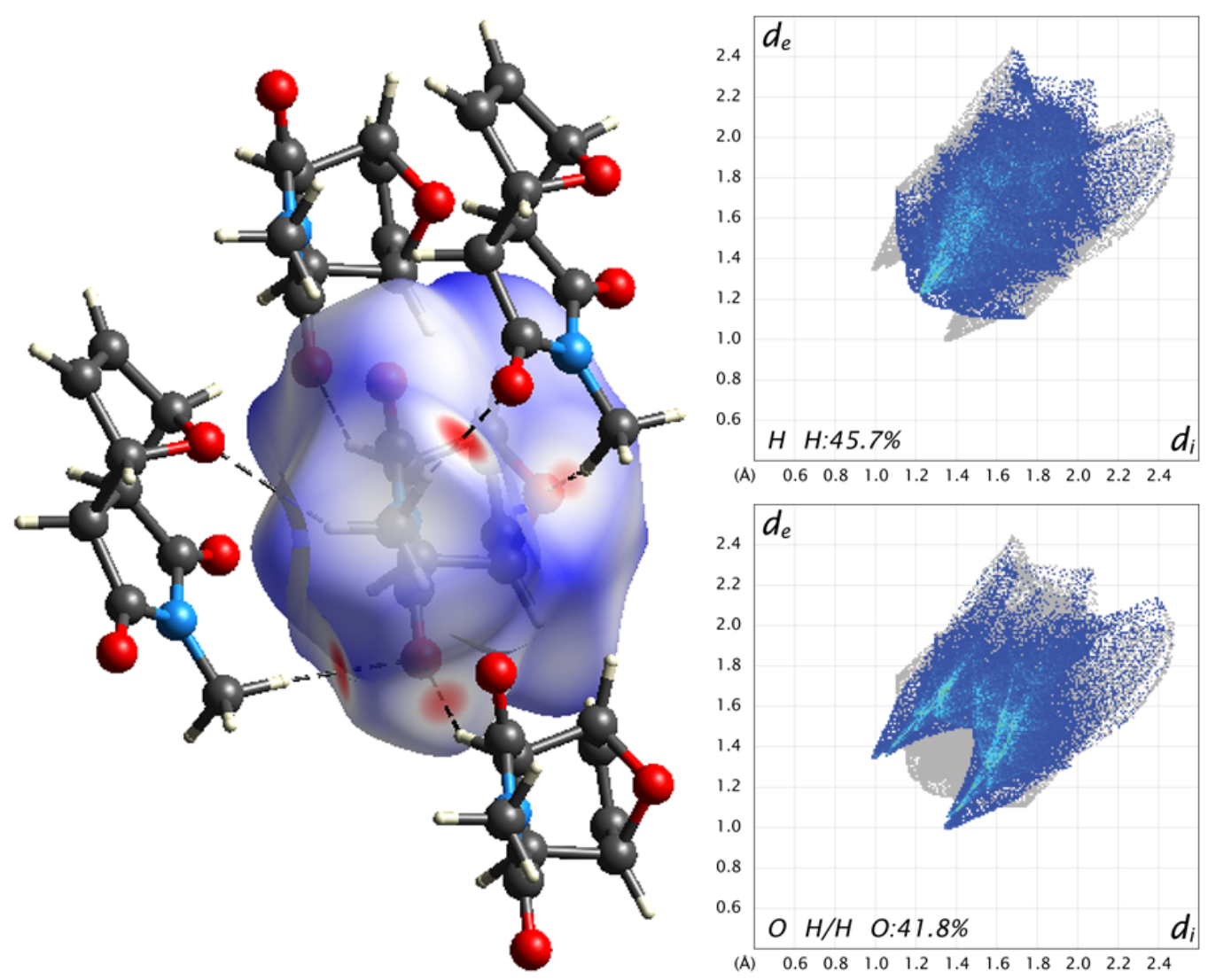

Şekil 7. Ekso izomer için Hirshfeld yüzeyi ve parmak izi histogramları (en büyük katkıya sahip olan etkileşmelere ait histogramlar gösterilmektedir.

\section{Sonuçlar ve Öneriler}

Çalışmaya konu olan bileşik bir epoksiizoindol türevidir. Bileşiğin moleküler yapısı 2008 yılında Goh ve arkadaşları tarafından yayınlanan makalede aydınlatılııştır (Yit, Pool and White, 2008). Bizim çalışmamızda molekül teorik olarak incelenmiştir. Elde edilen geometrik bulgular deneysel bulgularla karşılaştırılmıştır. X-Işını kırınımı metodu sonucunda elde edilmiş olan geometrik parametrelerle optimizasyon sonucunda elde edilen geometrik parametreler arasında önemli farklar görülmemektedir. Her iki izomer için HOMO-LUMO enerjileri hesaplanmıştır. HOMO-LUMO enerji aralığı endo izomer için $-6.07 \mathrm{eV}$, ekso izomer için $-6.12 \mathrm{eV}$ olarak hesaplanmıştır. Elektrostatik potansiyel yüzeyleri incelendiğinde negatif elektrostatik potansiyel bölgelerinin oksijen atomlarının üzerinde yoğunlaştığı görülmektedir. Hirshfeld yüzeyleri ve parmak izi histogramları moleküller arası yakınlaşmaların oksijen atomlarının olduğu bölgede olduğunu ve dolayısıyla kristal yapının oluşmasında C-H...O tipi hidrojen bağlarının önemli bir rol oynadığını göstermektedir. 


\section{Teşekkür}

Bu çalışma Giresun Üniversitesi Bilimsel Araştırma Projeleri Ofisi tarafından desteklenmiştir (FEN-BAP-A-140316-36).

\section{Kaynaklar}

Becke, A. D. (1992) 'Density-functional thermochemistry. II. The effect of the Perdew-Wang generalized-gradient correlation correction', The Journal of Chemical Physics, 97(12), p. 9173. doi: 10.1063/1.463343.

Chen, Y. J., Chang, W. M., Liu, Y. W., Lee, C. Y., Jang, Y. H., Kuo, C. D. and Liao, H. F. (2009) 'A small-molecule metastasis inhibitor, norcantharidin, downregulates matrix metalloproteinase-9 expression by inhibiting Sp1 transcriptional activity in colorectal cancer cells', Chemico-Biological Interactions, 181(3), pp. 440-446. doi: 10.1016/j.cbi.2009.07.004.

Cheng, S. S., Shi, Y., Ma, X. N., Xing, D. X., Liu, L. D., Liu, Y., Zhao, Y. X., Sui, Q. C. and Tan, X. J. (2016) 'Synthesis, crystal structure, spectroscopic properties and potential anti-cancerous activities of four unsaturated bis-norcantharimides', Journal of Molecular Structure. Elsevier B.V, 1115, pp. 228-240. doi: 10.1016/j.molstruc.2016.02.093.

Dennington, R., Keith, T. and Milliam, J. (2009) 'GaussView, Version 5', Semichem Inc., Shawnee Mission, KS.

Frisch, M. J.; Trucks, G.W.; Schlegel, H. B.; Scuseria, G. E.; Robb, M. A.; Cheeseman, J. R.; Scalmani, G.; Barone, V.;Mennucci, B.; Petersson, G. A.; Nakatsuji, H.; Caricato, M.; Li, X.; Hratchian, H. P.; Izmaylov, A. F.; Bloino, J.; Zheng, G.; Sonnenber, D. J. (2009) 'Gaussian 09', Gaussian, Inc. Wallingford CT, pp. 2-3. doi: 111.

Gurven, M. and Hill, K. (2010) 'Moving beyond Stereotypes of Men's Foraging Goals', Current Anthropology, 51(2), pp. 265-267. doi: 10.1016/j.ijpharm.2013.05.052.

Kadioglu, O., Kermani, N. S., Kelter, G., Schumacher, U., Fiebig, H. H., Greten, H. J. and Efferth, T. (2014) 'Pharmacogenomics of cantharidin in tumor cells', Biochemical Pharmacology. Elsevier Inc., 87(3), pp. 399-409. doi: 10.1016/j.bcp.2013.10.025.

Lee, C., Yang, W. and Parr, R. G. (1988) 'Development of the Colle-Salvetti correlation-energy formula into a functional of the electron density', Physical Review B, 37(2), pp. 785-789. doi: 10.1103/PhysRevB.37.785.

Li, M., Xu, X., Lu, F. and Guo, S. (2014) 'Primary in vitro and in vivo evaluation of norcantharidinchitosan/poly (vinyl alcohol) for cancer treatment', Drug Delivery, 21(4), pp. 293-301. doi: 10.3109/10717544.2013.840692.

Liu, X., Han, M., Xu, J., Geng, S., Zhang, Y., Ye, X., Gou, J., Yin, T., He, H. and Tang, X. (2017) 'Asialoglycoprotein receptor-targeted liposomes loaded with a norcantharimide derivative for hepatocyteselective targeting', International Journal of Pharmaceutics. Elsevier B.V., 520(1-2), pp. 98-110. doi: 10.1016/j.ijpharm.2017.02.010.

Tarleton, M., Gilbert, J., Sakoff, J. A. and McCluskey, A. (2012) 'Synthesis and anticancer activity of a series of norcantharidin analogues', European Journal of Medicinal Chemistry. Elsevier Masson SAS, 54, pp. 573-581. doi: 10.1016/j.ejmech.2012.06.010.

Wolff, S. K., Grimwood, D. J., McKinnon, J. J., Turner, M. J., Jayatilaka, D. and Spackman, M. A. (2012) 'CrystalExplorer (Version 3.1)'. University of Western Australia.

Yang, P. Y., Chen, M. F., Kao, Y. H., Hu, D. N., Chang, F. R. and Wu, Y. C. (2011) 'Norcantharidin induces apoptosis of breast cancer cells: Involvement of activities of mitogen activated protein kinases and signal transducers and activators of transcription', Toxicology in Vitro. Elsevier Ltd, 25(3), pp. 699-707. doi: 10.1016/j.tiv.2011.01.011.

Yit, W. G., Pool, B. R. and White, J. M. (2008) 'Structural studies on cycloadducts of furan, 2methoxyfuran, and 5-trimethylsilylcyclopentadiene with maleic anhydride and N-methylmaleimide', Journal of Organic Chemistry, 73(1), pp. 151-156. doi: 10.1021/jo7018575.

Zeng, Q. and Sun, M. (2009) 'Poly(lactide-co-glycolide) nanoparticles as carriers for norcantharidin', Materials Science and Engineering C. Elsevier B.V., 29(3), pp. 708-713. doi: 10.1016/j.msec.2009.01.004. 
Zhao, J., Guan, X. W., Chen, S. W. and Hui, L. (2015) 'Synthesis and biological evaluation of norcantharidin derivatives as protein phosphatase-1 inhibitors', Bioorganic and Medicinal Chemistry Letters. Elsevier Ltd, 25(2), pp. 363-366. doi: 10.1016/j.bmcl.2014.11.032. 